\section{Node Type Development of Four Low-chill Peach Cultivars at Three Locations in Florida}

\author{
Todd W. Wert, Jeffrey G. Williamson ${ }^{1}$, Jose X. Chaparro, \\ and E. Paul Miller \\ Department of Horticultural Sciences, University of Florida, 2113 Fifield \\ Hall, Hull Road, Gainesville, FL 32611
}

\author{
Robert E. Rouse \\ Southwest Florida Research and Extension Center, University of Florida, \\ Immokalee, FL 34142
}

Additional index words. Prunus persica, subtropical, flower initiation, blind nodes

\begin{abstract}
The effect of climate was observed on the relative frequency of vegetative and floral buds in four low-chill peach cultivars ('Flordaprince', 'Flordaglo', 'UFGold', and 'TropicBeauty'). The trees were planted in north-central, central, and southwest Florida. The percentage of blind nodes, mixed nodes (nodes with vegetative and floral buds), and nodes with only vegetative buds were determined from three representative shoots per tree at each location. In general, higher percentages of blind nodes were observed in central and southwest Florida and higher percentages of mixed nodes were observed in north-central Florida. 'TropicBeauty' tended to have a greater percentage of blind nodes than the other cultivars. Higher temperatures during bud formation most likely contributed to the increased amounts of blind nodes observed in the central and southwest locations and to the reduced amounts of mixed nodes. However, stresses imposed by bacterial spot and hurricanes may have contributed to the higher incidence of blind nodes in 2005 . Our results indicate that certain genotypes have a predisposition for the formation of blind nodes. Advanced selections having low chilling requirements and potentially being adapted to a wide diversity of tropical or subtropical climates need to be tested in multiple locations to evaluate blind node formation.
\end{abstract}

Climate is one of several factors that can greatly influence growth and development of reproductive organs, which in turn can have an effect on crop yield. The effects of climate on reproductive growth have been observed in many diverse crops. George et al. (1994) reported that larger flowers were produced at lower temperatures in persimmon. Low temperatures have also been reported to cause abnormalities in flower development in pepper (Polowick and Sawhney, 1985). In almond, a condition known as non infectious bud failure has been attributed to environmental factors such as warm temperatures (Kester and Asay, 1978). This condition can result in erratic canopy development and is often called crazy top.

The percentage of vegetative, floral, and blind nodes can indicate which cultivars are adapted to a climatic zone and which cultivars have a high cropping potential. Peaches initiate their floral and vegetative buds in the summer and fall before flowering (Raseira and Moore, 1987). Generally, a node on a mature peach tree consists of a single vegetative bud flanked on both sides by a flower bud. However, different combinations of flower and vegetative buds can occur: nodes with a

Received for publication 3 Apr. 2007. Accepted for publication 7 Aug. 2007.

${ }^{1}$ To whom reprint requests should be addressed; e-mail jgrw@ufl.edu vegetative bud and one or more flower buds, nodes with a single flower bud, or nodes that are blind. A blind node is defined as a node without vegetative or floral buds (Boonprakob et al., 1996). Blind nodes are more prevalent in subtropical or tropical regions versus temperate regions. Boonprakob et al. (1996) concluded that blind node formation was not attributable to a failure of bud initiation, but was the result of a failure of the buds to differentiate. Similar to that reported for noninfectious bud failure, blind nodes appear to be incited by high temperatures during bud development (Boonprakob and Byrne, 1990).

The objective of this study was to evaluate the performance of four low-chill peach cultivars at three locations in Florida with respect to the percentages of nodes with only vegetative buds, mixed nodes (nodes with vegetative and floral buds), and blind nodes set within each location.

\section{Materials and Methods}

Three sites were chosen that represented different chilling zones from north-central to south Florida. The north-central site was located in Archer, FL (Lake fine sand, $\left.29^{\circ} 31^{\prime} 12^{\prime \prime} \mathrm{N}, 82^{\circ} 31^{\prime} 48^{\prime \prime} \mathrm{W}\right)$ and typically accumulates 420 to 540 chill units (CU). The central site located in Winter Garden, FL (Calander fine sand, $28^{\circ} 34^{\prime} 12^{\prime \prime} \mathrm{N}$, single vegetative bud, nodes with a single $81^{\circ} 34^{\prime} 48^{\prime \prime} \mathrm{W}$; elev. $32.0 \mathrm{~m}$ ) typically accumulates 210 to $310 \mathrm{CU}$. The third or southwest location was located in Immokalee, FL (Immokalee fine sand, $26^{\circ} 25^{\prime} 48^{\prime \prime} \mathrm{N}$, $81^{\circ} 24^{\prime} 36^{\prime \prime} \mathrm{W}$ ) and typically accumulates 50 to $110 \mathrm{CU}$. The cultivars, 'Flordaglo', 'Flordaprince', 'TropicBeauty', and 'UFGold', vary slightly in chilling requirement and range from $\approx 150$ to $200 \mathrm{CU}$. All trees were grafted onto a rootknot, nematode-resistant rootstock (Fl 9-04). Trees were planted in February 2002 at all locations using a northsouth row orientation at a distance of $4.57 \mathrm{~m}$ between trees ( 346 trees/ha) in a randomized complete block design using single tree plots and five replications of each cultivar.

Locally recommended horticultural practices were used for weed, insect, and disease control. Trees were winter-pruned in early January and summer-pruned in early June as needed. Granular fertilizer $(12 \mathrm{~N}-1.75 \mathrm{P}-$ $6.6 \mathrm{~K})$ at the north-central Florida site was applied by hand in three applications during early February, early June, and late September. Additional applications of granular fertilizer from an adjacent commercial blueberry field occurred eight times from a mechanical fertilizer spreader on the east side of the trees. When the fertilizer was handbroadcast at the north-central location, it was placed primarily under the west half of the trees to compensate for the unequal distribution of fertilizer from the blueberry field. Hand-broadcast fertilizer application times in central Florida were similar to those at the north-central location. Reclaimed water was used for irrigation at this location. Total amount of nitrogen applied through reclaimed irrigation water was obtained by calculating the average nitrogen $(\mathrm{N})$ concentration of reclaimed water $\left(0.0072 \mathrm{~g} \cdot \mathrm{L}^{-1}\right.$ of $\mathrm{N})$. Emitter output, line pressure, and the irrigation schedule were used in determining the total amount of nitrogen applied per hectare through reclaimed water. This was calculated to be $33.86 \mathrm{~kg} \cdot \mathrm{ha}^{-1}$ per season. At the southwest location, a $16 \mathrm{~N}-4.4 \mathrm{P}-13.3 \mathrm{~K}$ controlled-release fertilizer was applied in March followed by an application of ammonium sulfate during each year. Annual nitrogen fertilizer rates during the study were $\approx 168 \mathrm{~kg} \cdot \mathrm{ha}^{-1}$ (north-central Florida), 103 $\mathrm{kg} \cdot \mathrm{ha}$ (central Florida), and $110 \mathrm{~kg} \cdot \mathrm{ha}$ (southwest Florida).

Temperatures were recorded in north-central and central Florida with a $\mathrm{HOBO}^{\circledR} \mathrm{H} 8$ Pro Series temperature sensor (Onset Computer Corp., Bourne, MA) starting the first week in November and ending the last week of May. At the southwest location, temperatures were obtained from a FAWN (Florida Automated Weather Network) station. Chilling (hours below $7.2^{\circ} \mathrm{C}$ ) was determined within each location starting during the first week of November and ending on 31 Jan.

Three shoots representing growth that occurred the previous summer and fall were selected after the completion of winter pruning but before budbreak. Shoots were typically located at a height of 1.5 to $2 \mathrm{~m}$. For each shoot, every node was examined and the 
A

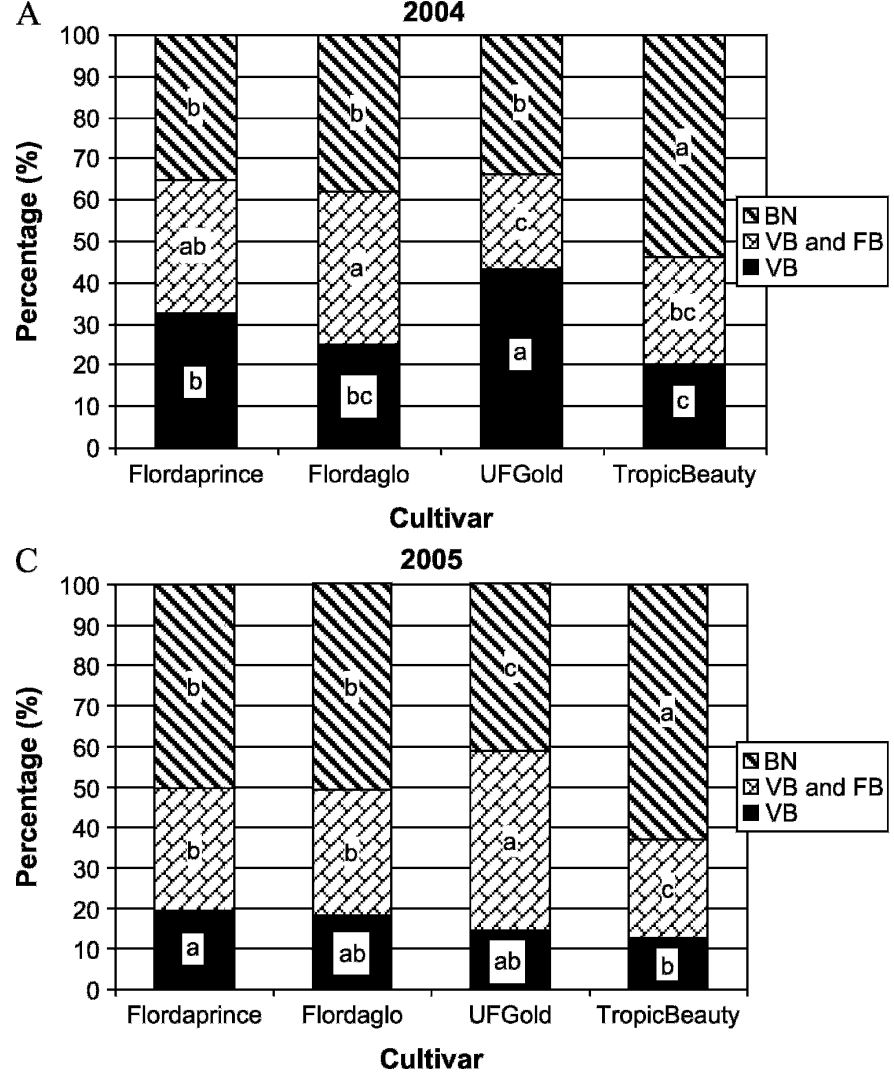

B
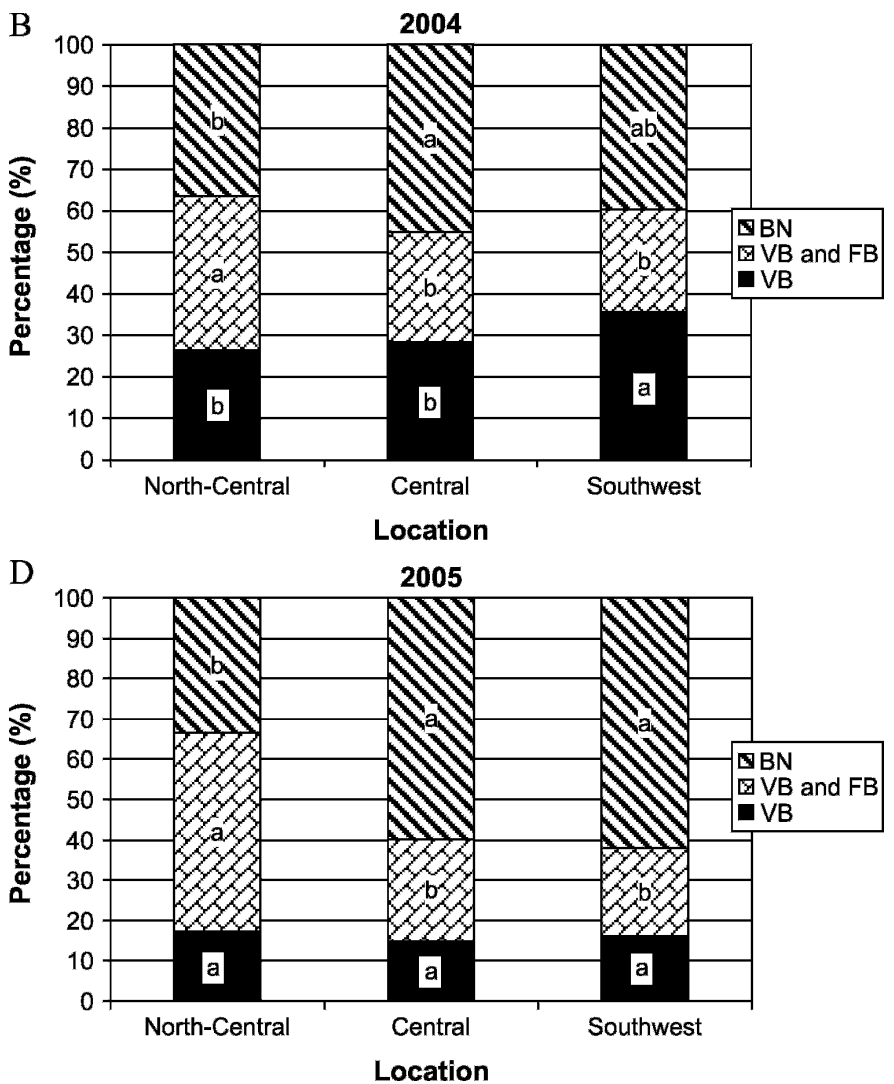

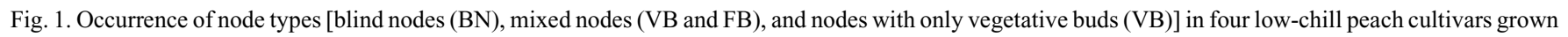
in three locations in Florida during the spring of 2004 and 2005. Lowercase letters indicate significant differences among cultivars according to Tukey's test $(P<0.05)$.

buds present at each node were determined to be vegetative only, vegetative with one floral bud, vegetative with two floral buds, or blind (vegetative and floral buds absent). The total number of each node type was determined for all the selected shoots on each tree. During the spring of 2005 , it was noted that several nodes had groupings with single, double, or triple floral buds without vegetative buds. The procedure was changed slightly to account for these node classifications. The data were used to estimate the percentages of nodes with only vegetative buds, mixed nodes, and nodes that were blind.

Statistical analysis was performed using the procedure PROC GLM in SAS 9.1 (SAS Institute, Cary, NC). Mean separations among and within the locations were determined by Tukey's honestly significant difference test at the $P \leq 0.05$ level. Correlations for the percentage of blind and mixed nodes, and mean August temperatures, were determined using PROC CORR.

\section{Results and Discussion}

Interactions for the percentage of node type were either nonsignificant or quantitative; therefore, only the main effects of cultivar and location are presented for each year. During 2004, 'TropicBeauty' had a greater percentage of blind nodes than the other cultivars (Fig. 1A). Differences in percentage of blind nodes were not observed among

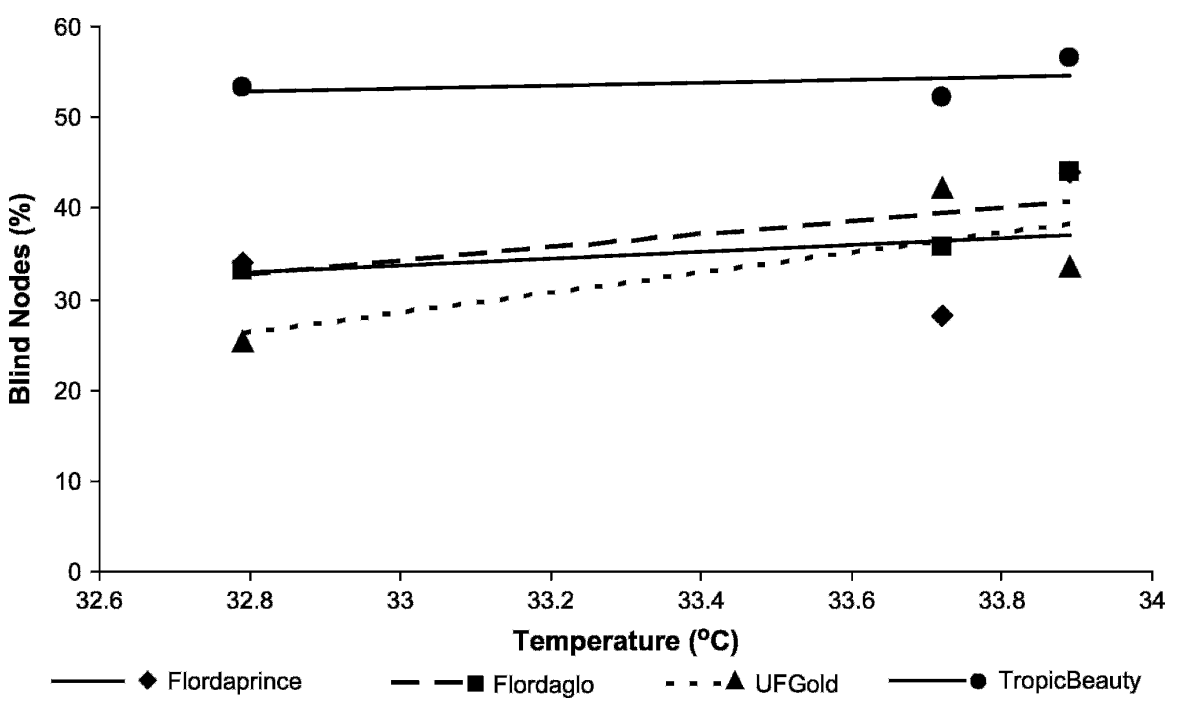

Fig. 2. Correlations between the percentage of blind nodes for 2004 and mean August temperature during 2003 for four low-chill peach cultivars in three locations. $r$ values are as follows: 'Flordaprince' $\mathrm{r}=$ 0.193 , 'Flordaglo' $r=0.349$, 'UFGold' $r=0.559$, ‘TropicBeauty' $r=0.100$. Each data point represents the mean of five values $(\mathrm{n}=15)$.

'Flordaprince', 'Flordaglo', or 'UFGold'. 'Flordaglo' had a significantly greater percentage of mixed nodes than 'UFGold' or 'TropicBeauty', whereas 'UFGold' had a significantly higher percentage of nodes with only vegetative buds. 'TropicBeauty' had the lowest percentage of nodes with only vegetative buds.
Node type also differed among sites. A higher percentage of blind nodes was observed at the central location compared with the north-central location (Fig. 1B). The opposite was true for mixed nodes in which a higher percentage was observed at the northcentral location compared with the other locations. Significant differences among 
locations were also observed for nodes with only vegetative buds with the highest percentage of these nodes observed at the southwest location.

Similarly, during 2005, a significantly higher percentage of blind nodes was observed for 'TropicBeauty' than for the other cultivars; however, in contrast to 2004, 'UFGold' had the lowest percentage of blind nodes (Fig. 1C). 'UFGold' also had the greatest percentage of mixed nodes, whereas the opposite was true for 'TropicBeauty'. 'Flordaprince' had a higher percentage of nodes with only vegetative buds than 'TropicBeauty'.

Differences were also observed among sites in 2005. A significantly lower percentage of blind nodes was observed in northcentral Florida than at the other locations (Fig. 1D). The north-central location also had a significantly higher percentage of mixed nodes compared with the other sites. Site differences for nodes with only a vegetative bud were not observed.

Using mean August temperatures at the three sites, the relationship between mean August temperatures and the percentage of blind nodes is shown in Figures 2 and 3 in which the proportion of blind nodes increases as mean August temperatures increase. Similar relationships between blind nodes and mean August temperatures were observed for both seasons; however, the trend was stronger during 2005. Among the cultivars, 'TropicBeauty' seemed to be affected most. When mean August temperatures were regressed on the percentages of mixed nodes, a strong correlation was observed during 2005 but not during 2004 (Figs. 4 and 5). In general, the percentage of mixed nodes decreased during both years when mean August temperatures increased during bud formation.

Warmer temperatures during bud development were probably the primary cause for the higher percentages of blind nodes observed in central and southwest Florida. Blind nodes are generally incited by high temperatures during a period of rapid shoot growth (Richards et al., 1994). Average temperatures above $20{ }^{\circ} \mathrm{C}$ are common in many areas of southern Florida during late summer and early fall, which is a critical time for bud formation. Average temperatures above $22{ }^{\circ} \mathrm{C}$, as well as other stresses imposed on trees, can be critical in the development of blind nodes (Boonprakob and Byrne, 2003). Conversely, the higher percentage of mixed nodes observed at the north-central location was most likely a result of cooler temperatures during bud formation. We observed stresses from both environment and disease during the summer and fall of 2004. The incidence of bacterial spot was high at the central Florida location. Infection and defoliation had already begun in May. The trees were not sprayed at this time because fruit were still being harvested. A spray program to control bacterial spot was initiated in early June when harvest was completed. Moreover, during 2004, several

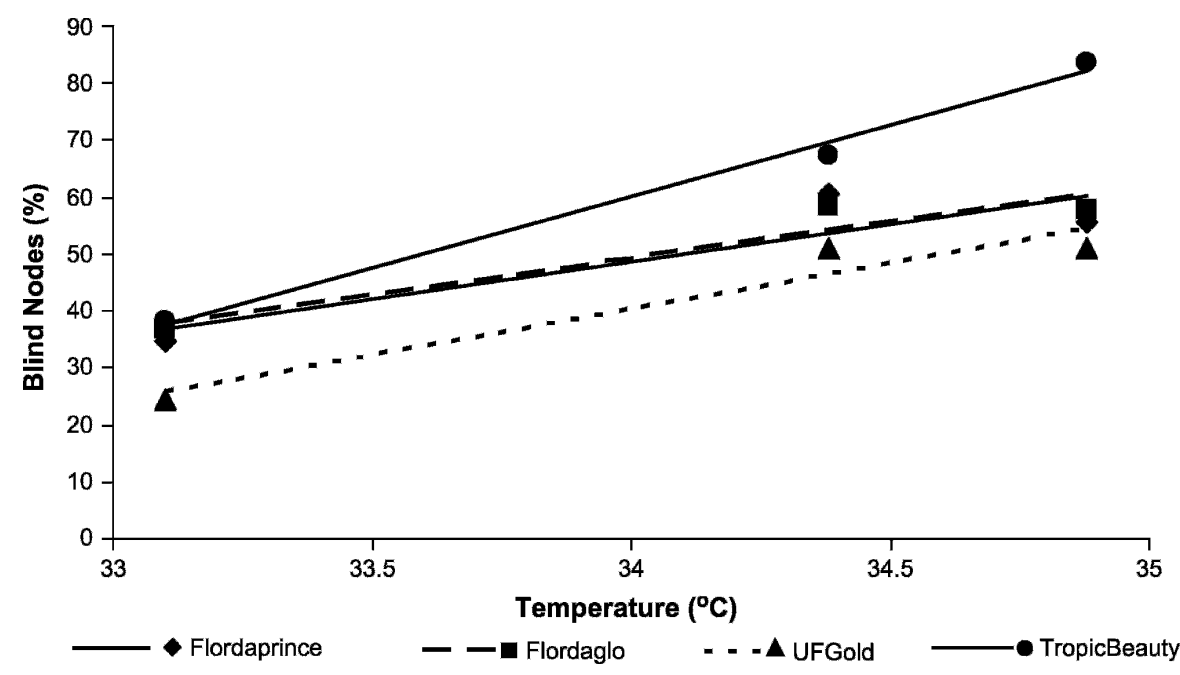

Fig. 3. Correlations between the percentage of blind nodes for 2005 and mean August temperature during 2004 for four low-chill peach cultivars in three locations. $r$ values are as follows: 'Flordaprince' $r=$ 0.742 , 'Flordaglo' $r=0.785$, 'UFGold' $r=0.794$, 'TropicBeauty' $r=0.970$. Each data point represents the mean of five values $(n=15)$.

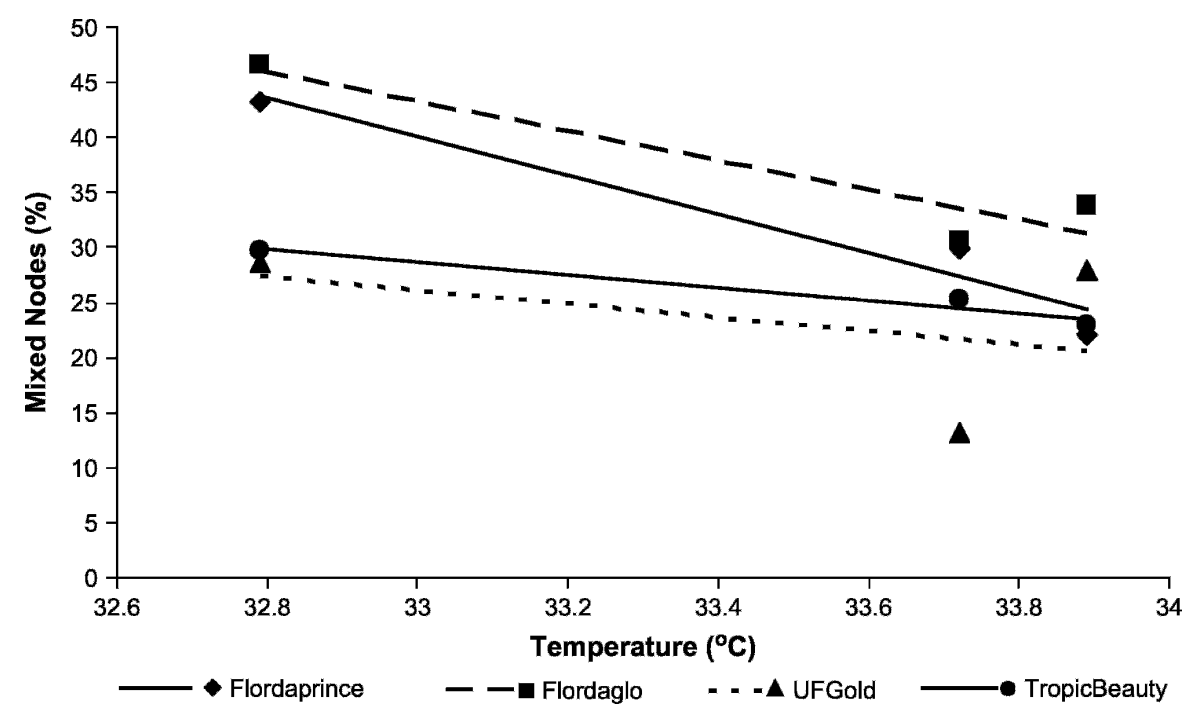

Fig. 4. Correlations between the percentage of mixed nodes in 2004 and mean August temperature during 2003 for four low-chill peach cultivars in three locations. $r$ values are as follows: 'Flordaprince' $r=$ 0.569 , 'Flordaglo' $r=0.679$, 'UFGold' $r=0.400$, 'TropicBeauty' $r=0.341$. Each data point represents the mean of five values $(n=15)$.

hurricanes (Category 2 or higher before landfall) passed through the location. Hurricanes Charley, Frances, and Jeanne caused leaf damage and defoliation at all three orchard locations. These storms likely increased the spread of bacterial spot within each tree and among trees.

The higher temperatures observed during late summer are probably the primary cause for the higher percentages of blind nodes observed in the central or southwest locations each year. However, we cannot dismiss the potential effects of other stresses such as bacterial leaf spot and high winds.

Genotypic differences for incidence of blind nodes appear to exist among cultivars. Richards et al. (1994) reported that the percentage of blind wood in a sample of 73 peach genotypes varied from $10 \%$ to $85 \%$ at Gainesville, FL, which has a climate similar to the north-central Florida location. Similarly Boonprakob et al. (1994) reported that blind wood ranged from $8.1 \%$ to $81 \%$ in 20 peach genotypes in Texas. In our experiments, 'TropicBeauty' tended to have the highest percentage of blind nodes and the strongest correlation with warmer temperatures. We observed a low percentage of blind nodes in 'UFGold'; this is in agreement with published information that states that few blind nodes are set by this cultivar (Sherman and Lyrene, 1997). This cultivar may have the ability to set both vegetative and flower buds under warmer conditions or severe environmental stresses.

Testing of different cultivars at multiple locations can help to determine their range of adaptation. The prevalence for the increased proportion of blind nodes can be cultivar-specific and some genotypes have a 


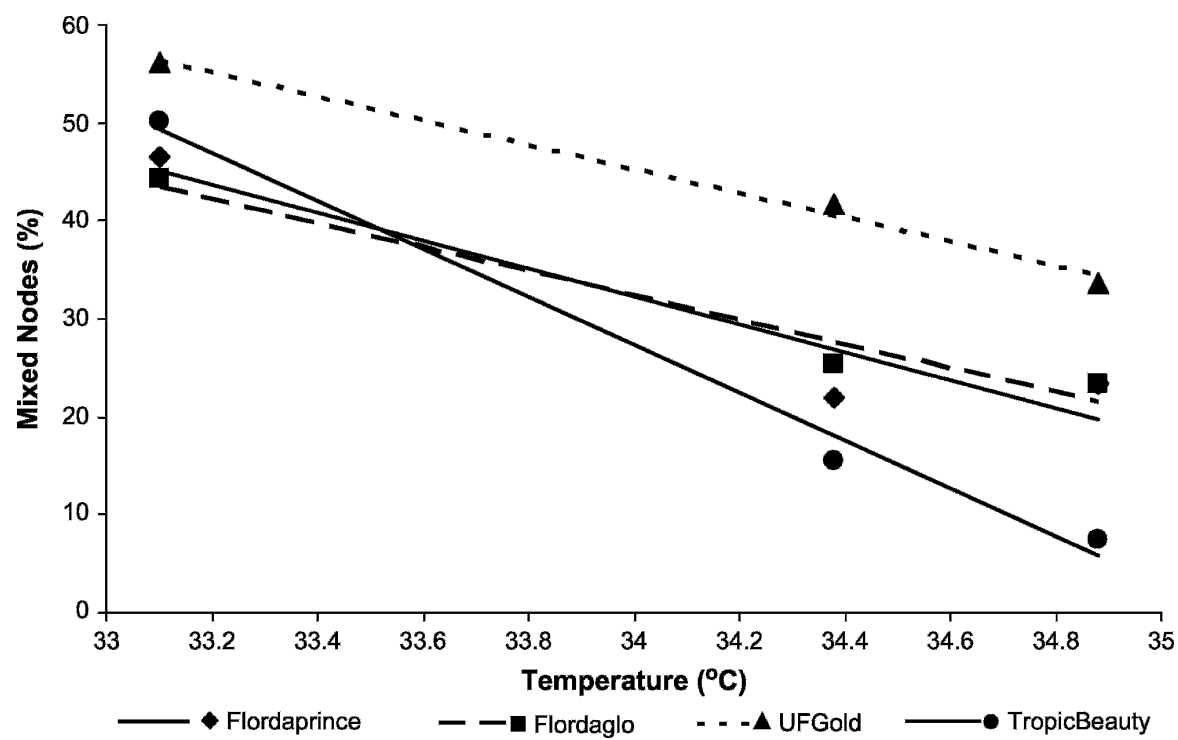

Fig. 5. Correlations between the percentage of mixed nodes in 2005 and mean August temperature during 2004 for four low-chill peach cultivars in three locations. $r$ values are as follows: 'Flordaprince' $r=$ 0.782, 'Flordaglo' $r=0.825$, 'UFGold' $r=0.679$, 'TropicBeauty' $r=0.977$. Each data point represents the mean of five values $(n=15)$.

predisposition for this trait. Our results indicate that warmer temperatures during the critical stage of bud formation in late summer increase the prevalence of blind nodes and cooler temperatures favor the development of mixed nodes. These differences in vegetative and reproductive growth have large impacts

\section{Literature Cited}

Boonprakob, U. and D.H. Byrne. 1990. Blind nodes in peach: Environmental and genetic parameters. HortScience 25:1068.

Boonprakob, U. and D.H. Byrne. 2003. Temperature influences blind node development in peach. Acta Hort. 618:463-467.

Boonprakob, U., D.H. Byrne, and D.M.J. Muller. 1996. Anatomical differences of axillary bud development in blind nodes and normal nodes in peach. HortScience 31:798-801.

Boonprakob, U., D.H. Byrne, and R.E. Rouse. 1994. A method for blind wood evaluation. Fruit Varieties Journal 48:213-215.

George, A.P., R.J. Nissen, and R.J. Collins. 1994 Effects of temperature and pollination on growth, flowering and fruit set of the non-astringent persimmon cultivar 'Fuyu' under controlled temperatures. J. Hort. Sci. 69:225-230.

Kester, D.E. and R.N. Asay. 1978. Variability in noninfectious bud-failure of 'Nonpareil' almond. I. Location and environment. J. Amer. Soc. Hort. Sci. 103:377-382.

Polowick, P.L. and V.K. Sawhney. 1985. Temperature effects on male fertility and flower and fruit development in Capsicum annum L. Scientia Hort. 25:117-127.

Raseira, M.C.B. and J.N. Moore. 1987. Time of flower bud initiation in peach cultivars differing in chilling requirement. HortScience 22:216-218. selections and breeding lines should be tested in multiple locations with diverse climates to see if they are prone to an increased amount of blind nodes and can withstand severe environmental stresses and still have the ability to set buds.
Richards, G.D., G.W. Porter, J. Rodriguez-A, and W.B. Sherman. 1994. Incidence of blind nodes in low-chill peach and nectarine germplasm. Fruit Varieties Journal 48:199-202.

Sherman, W.B. and P.M. Lyrene. 1997. 'UFGold' peach. Fruit Varieties Journal 51:76-77. 